\title{
Preventing perinatal infections
}

\author{
Need for a simple, inexpensive, safe intervention that can be used routinely in all \\ women
}

ecent research has highlighted several promising interventions to reduce perinatal infections. Unfortunately, many of these interventions are unaffordable for or inaccessible to women in developing countries, who bear the brunt of these infections, particularly the HIV epidemic. Limiting factors are the cost of the intervention, the cost or availability of diagnostic tests on which some interventions depend, and women's access to health services, particularly before the start of labour. Cost effective alternatives are needed.

Of major concern is the need for methods to reduce perinatal transmission of HIV. Treatment of mother and neonate with zidovudine was effective in one small randomised trial ${ }^{1}$ and has become the standard of care in many developed countries. Combination antiretroviral therapy is yet to be assessed in this situation. These treatments are unaffordable for most women in developing countries. Short course antiretroviral therapy is being investigated in several trials and, if shown to be effective, may offer a compromise.

Data from non-randomised studies suggest that avoiding breast feeding also reduces the transmission of HIV. This intervention may not be implementable widely in many developing countries because of the lack and the dangers of alternative feeding methods. Advice on breast feeding needs to be adapted to the individual situation and the informed choice of the woman. In the light of recent reports of late postnatal transmission occurring after 6 months of age in breast fed infants, ${ }^{2}$ theoretical alternatives such as early weaning (before the possible protective effect of passively transferred antibodies diminishes) need to be investigated.

Elective caesarean section may reduce the risk of infection of the infant. There is evidence for this in some prospective follow up studies of children born to mothers with HIV infection, although not in all. ${ }^{3}$ A multicentre randomised controlled trial is in progress. The protective effect of caesarean section may, at least in part, be related to an apparent association between rupture of membranes for longer than four hours and infection of the infant. ${ }^{4}$

Whether a conservative policy towards artificial rupture of membranes during labour would reduce vertical transmission of HIV is a question that needs urgent answering by means of a randomised controlled trial. This is particularly important because the active approach to the management of labour that originated in Dublin in the 1970s has been adopted enthusiastically in many developing countries, and reversal of the policy of early artificial rupture of the membranes would be an inexpensive "intervention."

Finally, cleansing of the birth canal with antiseptic during labour is an attractive, affordable option. A study by Taha and colleagues did not show an overall reduction in the rate of vertical transmission of HIV by use of $0.25 \%$ chlorhexidine cleansing. ${ }^{5}$ It did, however, demonstrate a significant reduction where membranes were ruptured for more than four hours, and more research on different antiseptics and formulations is indicated.

Infection with organisms other than HIV also have a major impact on perinatal morbidity and mortality. Antibiotic treatment of bacterial vaginosis diagnosed during pregnancy has been shown to reduce the rate of preterm birth. ${ }^{6}$ Diagnostic laboratory facilities are not essential: the simple amine ("whiff") test is a reliable indicator of bacterial vaginosis during pregnancy, making the intervention feasible in developing countries. Another risk factor for various perinatal infections is prelabour rupture of membranes. Systematic review of randomised trials has shown that use of oxytocin for rupture of membranes at or near term may reduce neonatal infection and admission rates to neonatal intensive care units. ${ }^{78}$

The management of women colonised with group B streptococcus remains problematic. The infection is usually asymptomatic, rates of serious neonatal infection are low in relation to the large number of carriers, and recolonisation after treatment is common. Systematic review of five randomised trials indicated that treatment during labour with antibiotics (usually $1 \mathrm{~g}$ of ampicillin given intravenously every six hours) reduced the incidence of early onset neonatal infection. ${ }^{9}$ Implementing this intervention depends on routine screening of asymptomatic women, which is expensive and depends on availability of laboratory facilities.

It is because of such problems that a simple, inexpensive, non-toxic intervention that can be used routinely in all women to reduce perinatal infections is attractive. In this week's BMJ (p 216), Taha and colleagues report further analyses ${ }^{10}$ from their earlier study. ${ }^{5}$ They find that perinatal infection and mortality were reduced during a three month period of cleansing the birth canal during labour with $0.25 \%$ chlorhexidine solution. This finding has enormous implications for obstetric practice worldwide. Because of the methodological shortcomings of the study 
(p 220), there is an urgent need (as for several of the interventions discussed above) for a large, multicentre randomised trial of birth canal cleansing to confirm its effectiveness.

\section{G Justus Hofmeyr Professor}

Department of Obstetrics and Gynaecology, Coronation Hospital, University of the Witwatersrand, South Africa

\section{James McIntyre Director}

Perinatal HIV Research Unit, Department of Obstetrics and Gynaecology, Baragwanath Hospital, University of the Witwatersrand, South Africa

1 Connor EM, Sperling RS, Gelber R, Kiselev P, Scott G, O'Sullivan MJ. Reduction of maternal-infant transmission of human immunodeficiency virus type 1 with zidovudine treatment. N Engl J Med 1994;331:1173-80.

2 Ekpini ER, Wiktor SZ, Satten GA, Adjorlolo-Johnson GT, Sibailly TS, Ou CY, et al. Late postnatal mother to child transmission of HIV-1 in Abidjan, Côte d'Ivoire. Lancet 1997;349:1054-9.

3 Newell M-L, Peckham C. Risk factors for vertical transmission of HIV-1 and early markers of HIV-1 infection in children. AIDS 1993;7(suppl 1):S91-7
4 Minkoff H, Burns DN, Landesman S, Youchah J, Goedent JJ, Nugent RP, et al. The relationship of the duration of ruptured membranes to vertical transmission of HIV. Am J Obstet Gynecol 1995;173:585-9.

5 Biggar RJ, Miotti PG, Taha TE, Mtimavalye L, Broadhead R, Justesen A, et al. Perinatal intervention trial in Africa: effect of a birth canal cleansing intervention to prevent HIV transmission. Lancet 1996;347:1647-50.

6 Hauth JC, Goldenberg RL, Andrew W. Reduced incidence of preterm delivery with metronidazole and erythromycin in women with bacterial vaginosis. N Engl J Med 1995;333:1732-6.

7 Hannah ME, Tan BP. Oxytocin for prelabour rupture of membranes at or near term. In: Neilson JP, Crowther CA, Hodnett ED, Hofmeyr GJ, Keirse MJNC, eds. Pregnancy and childbirth module of the Cochrane database of systematic reviews [updated 4 March 1997]. Available in: The Cochrane Library [database on disk or CD ROM]. Issue 2. Oxford: Oxford Update Software, 1997.

8 Hannah ME, Ohlsson A, Farine D, Hewson SA, Hodnett ED, Myhr TL, et al. Induction of labour compared with expectant management for prelabor rupture of membranes at term. N Engl J Med 1996;334:1005-10.

9 Smaill F. Intrapartum antibiotics for Group B streptococcal colonisation. In: Neilson JP, Crowther CA, Hodnett ED, Hofmeyr GJ, Keirse MJNC, eds. Pregnancy and childbirth module of the Cochrane database of systematic reviews [updated 4 March 1997]. Available in: The Cochrane Library [database on disk or CD ROM]. Issue 2. Oxford: Oxford Update Software, 1997.

10 Taha TE, Biggar RJ, Broadhead RL, Mtimavalye LAR, Justesen AB, Liomba GN et al. Effect of cleansing the birth canal with antiseptic solution on maternal and newborn morbidity and mortality in Malawi: clinical trial. $B M J$ 1997;315:216-9.

\title{
Regulating the pharmaceutical industry
}

\author{
Pricing should be renegotiated to control research costs and encourage cost \\ effectiveness
}

$\mathrm{T}$ The pharmaceutical price regulation scheme ${ }^{1}$ is a voluntary agreement between Britain's Department of Health and the Association of the British Pharmaceutical Industry in which companies negotiate generous target profit rates from sales of drugs to the NHS $(17-21 \%$ rate of return on investment in research and development). The scheme's objectives are to secure the provision of safe and effective medicines to the NHS at reasonable prices; to promote a strong pharmaceutical industry in Britain; and to encourage the efficient and competitive development and supply of medicines worldwide. ${ }^{1}$ The scheme was renewed in 1993 for five years and is currently under review. Although the scheme has been successful in helping to maintain the British pharmaceutical industry, its objectives conflict, and the way the scheme operates pays little regard to other health policy objectives. As the price of renegotiation, the government should request changes to the scheme, to minimise the inherent conflicts and to ensure that the scheme supports other policies.

There is considerable evidence of the scheme's success at achieving a strong industry. ${ }^{2}$ However, drug prices in Britain are higher than those in other countries, and there is much debate about what is a "reasonable" price for the NHS. For the Department of Health a conflict exists between its own attempts to control NHS expenditure and the scheme's implicit subsidy of the industry's research and development. If cost containment measures-such as encouraging the use of generic drugs, provision of prescribing data, and other policies aimed at general practitioners' prescribing-threaten profits, the price regulation scheme may allow companies to increase prices. The scheme may also reduce companies' incentives to control their research costs. Finally, there is no attempt to link prescribing with cost effectiveness: products that are cost effective and those that are not are treated equally under the scheme.

In renegotiating the continuation of voluntary profit regulation the government should require the industry to make four policy changes. Firstly, as supported in principle by the House of Commons Health Committee, ${ }^{3}$ a "fourth hurdle" of comparative cost effectiveness should be adopted by the NHS before it agrees to pay for new drugs. This has been required in Australia since $1993,{ }^{4}$ where new drugs with no advantage over existing products are offered at the same price. Where clinical trials show superiority, incremental cost effectiveness is assessed to determine whether a product represents value for money at the price sought.

The implementation of this type of hurdle in Britain requires restriction of publicly reimbursed drugs by a positive list. The existing voluntary guidelines for the economic evaluation of pharmaceuticals ${ }^{5}$ should be made compulsory for all new products. The cost of the studies and the reimbursement system should be met by industry. Studies should then be reviewed by independent researchers and a panel of medical professionals and economists. This would facilitate national prioritisation of drug treatments and avoid problems of differential access to new products such as interferon beta for multiple sclerosis and new drug treatments for Alzheimer's disease. ${ }^{6}$

The second suggestion is a more explicit annual report on the scheme to parliament. The first ever report was published in May 1996 and was opaque. In future this report should reveal not only the complicated way in which the scheme works but also its achievements in engendering efficient research and development within the industry. The real cost to the 
taxpayer of the scheme should be made explicit and be open to debate. The report should also log the number and novelty of the new products which have been produced over a specified period. Novelty-chemical and therapeutic-should be judged by an expert panel.

Thirdly, access to data generated by pharmaceutical companies' research programmes should be increased. Regulation should be introduced to ensure that all data relating to licensed drugs are made publicly accessible and all drug trials are registered prospectively with the Committee on Safety of Medicines and in the National Research Register. It is unethical to ask patients to participate in drug trials without the resulting information being made publicly available to guide their choices and future research and policy. Schering Health Care has already set an excellent precedent by making information about all its unpublished and current trials available through the Cochrane Controlled Trials Register.

Finally, if pharmaceutical industry research is to continue to be subsidised by taxpayers, policymakers should determine, at the margin, the prioritisation of research and innovation. The industry would be expected to respond to these stated priorities, aided by annual reporting of progress. Research within the priority areas could be taken into account in setting individual companies' profit targets within the scheme. Companies which did not address these research priorities could be penalised, generating funds which could be directed to universities via the Medical Research Council.

These four policy innovations will result in a more efficient scheme for regulating the British pharmaceu- tical industry, rewarding better the manufacturers of the most effective drugs through higher prices. The policies could also facilitate national prioritisation of drug treatments and increase the quality of information provided to prescribers and other NHS purchasers about new drugs. In time, as these innovations affect resource allocation, they may induce greater confidence that the goals of pharmaceutical policy, both industrial (increasing wealth) and health (improving population health), are being addressed. Without explicitness about the goals and performance of trade and health policies, drug expenditure will continue to inflate with little accountability and insufficient benefit for patients.

\section{Alan Maynard Professor of economics}

York Health Economics Consortium, University of York, York YO1 5DD

\section{Karen Bloor Research fellow in health economics}

Department of Health Sciences and Clinical Evaluation, University of York, York YO1 5DD

1 Department of Health. Pharmaceutical price regulation scheme. London: DoH/ABPI, 1993.

2 Martin S. The pharmaceutical price regulation schemes: an economic evaluation. York: University of York, 1995.

3 House of Commons. Priority setting in the NHS: the NHS drugs budget. Health Committee second report, session 1993-94. London: HMSO, 1994.

4 Commonwealth of Australia. Draft guidelines for the pharmaceutical industry on preparation of submissions to the Pharmaceutical Benefits Advisory Committee: including submissions involving economic analyses. Canberra: Department of Health, Housing and Community Services, 1990.

5 Department of Health. Guidelines for the economic evaluation of pharmaceuticals. London: Department of Health, 1994 (press release 94/251).

6 Kelly CA, Harvey RJ, Cayton H. Drug treatments for Alzheimer's disease. BMJ 1997;314:693-4.

\section{Misconduct in research: editors respond}

\section{The Committee on Publication Ethics (COPE) is formed}

$\mathrm{M}$ isconduct in research momentarily rose high up the agenda of the British medical community after Malcolm Pearce, an obstetrician and gynaecologist, was found in 1995 to have forged a series of papers. ${ }^{1}$ The case made the front pages of the newspapers and led to the downfall of a president of a royal college. Despite calls for action on research misconduct, ${ }^{2}{ }^{3}$ the issue has not been tackled. Now Britain has another high profile case, ${ }^{4}$ and perhaps the profession will be awakened from its torpor. In the meantime, editors-who are regularly confronted by cases of possible misconduct-have decided to help themselves. We have set up the Committee on Publication Ethics (COPE).

Last week John Anderton, a consultant physician in Edinburgh and former registrar and secretary of the Royal College of Physicians of Edinburgh, was struck off by the General Medical Council (GMC), which regulates medical practitioners in Britain, for faking data in a clinical trial (p 205). ${ }^{4}$ The misconduct came to light because of an investigation by a pharmaceutical company, Pfizer, for which he was conducting the research. The company was helped by the private agency set up to investigate possible cases of research misconduct that is associated with Frank Wells, former medical director of the Association of the British Pharmaceutical Industry. Dr Wells, a coauthor of the BMJ Publishing Group's book Fraud and Misconduct in Medical Research ${ }^{5}$ says that his agency is constantly busy. Its main customers are pharmaceutical companies and health authorities. Since 1989 Dr Wells has reported 17 cases to the GMC, all of which have resulted in findings of serious professional misconduct. The agency has another 12 cases pending.

In May Dr Peter Nixon, a consultant cardiologist from Charing Cross Hospital, London, admitted in court that errors in scientific papers cowritten by him appeared to be "more than an honest slip of the pen." ${ }^{6}$ Dr Nixon retired and told the GMC that he would not practice again. He may thus have escaped a council hearing. Importantly, Dr Nixon's admission emerged in a case in which he was the plaintiff not the defendant. He had spent three years suing a television programme for libel, and the Medical Defence Union faced a bill of some $£ 2 \mathrm{~m}$ after supporting him.

We still do not know how many cases of research misconduct there are in Britain, but it is becoming increasingly difficult to argue that cases are isolated 
and rare. The United States has many cases because it has more effective methods for identifying them. In Britain we seem to be leaving it to pharmaceutical companies, a private agency, and the media to discover most cases. Cases that emerge from investigations held by medical schools or royal colleges are vanishingly rare.

This is shameful. As Sir Donald Irvine, president of the GMC, has recently reminded us, self regulation is a privilege not a right. ${ }^{7}$ It has to be deserved, and we need to find better methods of responding to research misconduct not only to maintain public confidence in medical research but also to stop members of the public or parliament arguing that we no longer deserve self regulation. We need effective systems for preventing, detecting, and investigating research misconduct and for imposing punishment, and it will obviously be sensible to put the emphasis on preventing.

While we wait for an adequate response from the broader profession, the editors of Gut, BMJ, Lancet, British Journal of Anaesthesia, Journal of Bone and Joint Surgery, British Journal of Obstetrics and Gynaecology, and of other journals from the BMJ Publishing Group have set up COPE. Michael Farthing, the editor of Gut, prompted us to take this step after he encountered four cases of misconduct in his first year as editor. ${ }^{8}$ Most editors encounter problems of possible research misconduct and ethical misbehaviour, and we have had an informal network of telephoning each other to ask for advice. We thought that we might increase understanding, gather information that might be useful to the broader profession, and improve the quality of our responses to problems if we formalised the network.

COPE will serve editors rather than authors or readers, and its functions are shown in the box. It will help with ethical problems that are broader than research misconduct. We have chosen to serve editors because we have legitimacy to do that. COPE cannot be a substitute for a proper body to serve the full profession, and the committee will deal with anonymised cases. Individual editors will take whatever action they think is appropriate, but the committee will, I hope, urge editors not to take the easy (but traditional) route of simply rejecting questionable papers.

\section{Work of the Committee on Publication Ethics (COPE)}

The committee will:

Advise on cases brought by editors. Cases will be presented anonymously, and full responsibility will remain with the reporting editor

Consider cases related to advertising, authorship, confidentiality, conflict of interest, editorial freedom, editorial integrity, media relations, patient privacy, peer review, redundant publication, research ethics, and research misconduct

Publish an annual report on the cases it considers

Draft guidance on these issues

Promote research into publication ethics

Consider offering teaching and training

COPE is an experiment. It may not prove useful in the long term, and we will be delighted if it is made unnecessary because the international profession produces an adequate response to research misconduct. We have begun work already and will be holding a one day conference on journals and research misconduct in November** Editors everywhere are welcome to join COPE.

\section{Richard Smith Editor, BMJ}

* See advertisement for conference opposite p 215 in clinical research edition, p 216 in general practice edition, and p 199 in compact/international edition.

\footnotetext{
1 Lock S. Lessons from the Pearce affair: handling scientific fraud. BMJ 1995;310:1547-8.

2 Dealing with deception. Lancet 1996;347:843.

3 Smith R. Time to face up to research misconduct. BMJ 1996;312:789-90.

4 Dyer C. Consultant struck off over research fraud. BMJ 1997;315:205.

5 Lock S, Wells F, eds. Fraud and misconduct in medical research. London: BMJ Publishing, 1996.

6 Dyer C. Cardiologist admits research misconduct. BMJ 1997;314:1501.

7 Irvine D. The performance of doctors. I: Professionalism and self regulation in a changing world. $B M J$ 1997;314:1540-2.

8 Farthing MJG. Research misconduct. Gut 1997;41:1-2.
}

\section{User fees}

\section{They don't reduce costs, and they increase inequity}

$\mathrm{I}$ f user fees for health care are the solution, what exactly is the problem? Proponents of user fees recommend them in two situations. The first is when health spending in total is low or falling-fees are recommended as a way to mobilise more money for health care than existing sources provide. The second, paradoxically, is when health expenditure is high or rising quickly, when fees are recommended as a way of improving efficiency by moderating demand and containing costs. ${ }^{2}$ Opponents of user fees attack them as a political strategy for shifting healthcare costs from the better off to the poor and the sick, pointing to the trade off between this method of raising revenue and maintaining access to care based on need rather than ability to pay. ${ }^{3}$

Dramatic differences exist between countries. Levels of and trends in national income and the condition of health systems vary widely among countries, and local context needs to be considered when making comparisons. In many "transition" economies such as China, Kyrgyzstan, Georgia, and Vietnam formal and informal charging at "subsidised" (government) health facilities has been used to replace sharply declining public sector funds. In most of the very poor countries of sub-Saharan Africa fees have been raised or introduced, sometimes after years of commitment to "free health care," as a way 
to provide small but sometimes critical supplements to government health spending of less than $\$ 5$ per capita.

In these extreme situations fees have been a mechanism for finding additional funding. How successful have user fees been in this context? Measured as a percentage of total government health spending, income from user fees remains at less than $5 \%$ in most African countries, although it seems to be somewhat higher in Asia and has risen to as much as 36\% in China. ${ }^{4}$ But, overall, experience with fees as a device for raising revenue in poor and transitional countries is modest.

User fees can be costly to implement, and income based exemptions in particular have widely proved difficult to manage. ${ }^{5}$ Some major shifts in access to and use of health services have been recorded in several countries implementing a policy of user fees, with use in rural areas falling by over $50 \%$ a year for several years. ${ }^{6}$ Increases in maternal mortality (C Hongoro, S $\mathrm{K}$ Chandiwana, unpublished report) and in the incidence of communicable diseases such as diphtheria and tuberculosis have been attributed to such policies. ${ }^{7}$ A contemporary commentator said of Vietnam: Access to health care increasingly depends on income, ${ }^{8}$ and another said of China: Access to health care is largely based on the patient's ability to pay, and many cannot afford care. ${ }^{9}$

In the industrialised countries the context is one of comparative economic prosperity and stability and, in the main, of relatively well functioning and accessible health systems. Average per capita health spending in countries of the Organisation for Economic Cooperation and Development in 1995 was over $\$ 1500 .^{10} \mathrm{In}$ Western Europe all countries currently have some limited form of user fee policy, most commonly in the form of partial payment for drugs. ${ }^{11}$ Total levels of finance generated through fees for publicly subsidised care are difficult to assess but are probably not very different from those reported for African countries. Levels of spending on health care and growth rates differ among this group of countries, with Bismarckian insurance-based systems generally taking a larger share of gross domestic product and having faster growth rates than Beveridge-type national health systems.

\section{Limited success at managing demand}

In both types of system, but more so in NHS-type systems (Britain, Ireland, Italy, and Spain), overall control of costs has generally been relatively successful, either through mechanisms of financing through a single source with relatively hard budget limits or through ceilings on premium contributions and reform of provider payments; thus the role of user fees is much more as a tool for moderating demand than a source of revenue. As an instrument for controlling costs by managing demand, user fees have had limited success. From several industrialised countries ${ }^{12-14}$ there is evidence that increasing fees does reduce use of health services, though not necessarily service costs. Reduced use of services has sometimes been accompanied by increased intensity in the form of longer or more expensive treatment episodes. ${ }^{15}$ In the area of cost control, user fees seem to be a relatively weak policy tool because they focus on patients' behaviour rather than that of providers. Not only are providers a more powerful determinant of healthcare costs, by making decisions on behalf of patients for all but first contact visits, but changes on the supply side in purchasing and provider payment mechanisms have shown themselves to be more powerful ways of influencing providers' behaviour and service costs. ${ }^{11}$

\section{Profound effects on access}

And there remains the question of equity. Shifting the financing base in the health sector, even at the margin, can have profound effects on access to services. No country's experience shows this more clearly than China, where some 800 million people lost their health insurance protection during the 1980 s, when rural insurance collapsed and fees grew in importance from $24 \%$ to $36 \%$ of healthcare finance. User fees shift the financing burden away from population based, risk sharing arrangements-such as funding based on tax or social insurance-and towards payments by individuals and households. The higher the proportion of user payments in the total mix of financing for health, the greater the relative share of the financing burden falling on poor people. ${ }^{16}$ Poor people are both sicker and more sensitive to healthcare prices than wealthier people. A range of policy options other than user fees exists for dealing with situations of both underfinancing and rapid growth in expenditure. As an instrument of health policy, user fees have proved to be blunt and of limited success and to have potentially serious side effects in terms of equity. They should be prescribed only after alternative interventions have been considered.

\section{Andrew Creese Health economist}

Division of Analysis, Research and Assessment, World Health Organisation, CH-1211 Geneva 27, Switzerland

1 Shaw RP, Griffin C. Financing health care in sub-Saharan Africa through user fees and insurance. Washington, DC: World Bank, 1995.

2 Akin J, Birdsall N, Ferranti D. Financing health services in developing countries: an agenda for reform. Washington, DC: World Bank, 1987.

3 Evans RG, Barer ML, Stoddart GL. User fees for health care: why a bad idea keeps coming back. Toronto: CIAR Program in Population Health, 1993. (Working Paper 26.)

4 Dezhi Y. Changes in health care financing and health status: the case of China in the 1980s. Florence: Innocenti, 1992. (Occasional Paper No 34.)

5 Creese A, Kutzin J. Lessons from cost recovery in health. Geneva: World Health Organisation, 1995. SHS/NHP. Forum on Health Sector Reform (Discussion Paper No 2.)

6 Waddington C, Enyimayew KA. A price to pay, part 2: the impact of user charges in the Volta region of Ghana. Int J Health Plann Manage 1990, 5:287-312.

7 International Child Development Centre. Central and Eastern Europe in transition:public policy and social conditions. Regional monitoring report No 1. Florence: Unicef, 1993

8 Witter S. Doi Moi and health: the effect of economic reforms in the health system in Vietnam. Int J Health Plann Manage 1996;II:159-72.

9 Hsiao W, Liu Y. Economic reform and health lessons from China. N Engl J Med 1996;335:430-2.

10 OECD Health Data. OECD: Paris, 1997.

11 Kutzin J. What is the appropariate role for patient cost-sharing in European health care systems? In: Saltman R, Figneras J, Sakillavides C, eds Critical challenges for health systems in Europe. Oxford: Oxford University Press, (in press)

12 Nolan B. Economic incentives, health status, and health services utilisation. J Health Econ 1993;12:151-69.

13 Organisation for Economic Cooperation and Development. The reform of health care systems: a review of seventeen OECD countries. Paris: OECD, 1994. (Health Policy Studies No 5.)

14 Fahs MS. Physician response to the United Mine Workers' cost-sharing programme: the other side of the coin. Health Serv Res 1992;27:25-45.

15 Manning WG, Newhouse JN, Duan N, Keeler EB, Leibowitz A, Marquis MS. Health insurance and the demand for medical care: evidence from a randomized experiment. Am Econ Rev 1987;77:251-77.

16 Van Doorslaer E, Wagstaff A, Rutten F. Equity in the finance and delivery of health care: an international perspective. Oxford: Oxford University Press, 1993. 


\title{
When the next influenza pandemic comes
}

\author{
Be prepared, or procrastinate and panic
}

$\mathrm{A}$

$\mathrm{n}$ influenza virus may emerge against which most people in the world have no immunity. This will be the next influenza pandemic, with high attack rates in all ages, a risk of high death rates, and a heavy burden on health services. It is prudent to prepare for such a pandemic, particularly if there are actions that could prevent or reduce severe morbidity. At an international meeting in Washington in 1995, countries from around the world met to discuss their plans of attack.

Britain's health departments have now published their plans, ${ }^{1}$ revealing as much about the convoluted organisation of health services as about the epidemiology of influenza. The plans concentrate on the actions of central agencies, as a framework on which health authorities and trusts should make local plans. When most people working at the local level in the NHS are struggling with the existing workload and budgetary constraints, it is tempting to shy away from preparing for an influenza pandemic.

Previous pandemics have been due to influenza A viruses and have occurred at irregular intervals: 1889, 1918, 1957, and 1968. Influenza A viruses are named by their haemagglutins (H1, H2, etc), their neuraminidases (N1, N2, N3, etc), and the place and year where and when the strain was first identified. Hence, the 1968 pandemic virus was H2N3 influenza A/Hong Kong/68. The genetic shifts that create pandemic influenza viruses were discussed in a $B M J$ editorial in 1994. ${ }^{2}$

The plans refer to six phases of influenza pandemics. ${ }^{1}$ Phase 0 is the current state, between pandemics. Phase 1 is the emergence of a "new" influenza virus, in the past in the Far East. In phase 2 the new virus is causing outbreaks in other countries. The arrival of the new virus in Britain marks the start of phase 3. Phase 4 is pandemic influenza in Britain, and phase 5 is the post-pandemic review. The time from phase 1 to phase 4 is unpredictable. In the past it has taken a year, but the current levels of international travel encourage the global spread of infection. The re-emergence of H1N1 influenza A, which caused the 1918 pandemic, in Russia in 1977 illustrates how influenza viruses can reach phase 3 and then settle to phase 0 without causing a true pandemic.

The World Health Organisation coordinates the detection of influenza viruses around the world and is likely to be the agency which says that a new influenza virus has emerged. Internationally, this will trigger the development of new vaccines. Nationally, an influenza advisory committee will be convened. As soon as the new virus is causing outbreaks abroad, there will be a demand for vaccines and advice, especially for travellers to countries where the new viruses have emerged. In this phase, health authorities and boards and hospital trusts must ensure that their plans are up to date.

Before a pandemic influenza virus reaches Britain there must be agreement on the best use of vaccines and antiviral drugs. If the British policy on influenza

vaccine were broader, in accordance with the evidence on efficacy, ${ }^{3}$ British health services would be better prepared for a pandemic when actions must replace words. The plans do not analyse where the critical points lie. I suspect that they are the prompt supply of drugs in sufficient quantities to protect high priority groups, the credibility of the national influenza vaccine policy, and the capacity of hospitals and primary care services to cope with a huge demand for emergency medical care in mid-winter. In a pandemic, healthcare staff and other providers of essential services are top of the list for vaccination, but can the occupational health services in the NHS meet this task? Can general practices include the staff of nursing and residential homes for vaccination as well as the residents at high risk of spread and of severe disease?

There is a good case for a common set of local plans to be adopted countrywide by health authorities, hospital trusts, and primary healthcare teams. National guidance often recommends special plans for unusual events, whereas local plans for emergencies are most robust when they are based on normal good practice. The features of the familiar winter epidemics are a guide: autumnal promotion of influenza vaccine in general practice, laboratory detection of influenza viruses, and rises in consultations for influenzal illness that mark the arrival of an epidemic-when the press is excited, staff are away on sick leave, hospitals are full, and death rates climb to a peak. The local working groups on emergency admissions and the district infection control committees can be adapted to meet influenza pandemics. Local audits of influenza and pneumonia prevention will show where present arrangements are weak.

The complexity of health care in Britain may hamper quick action in an influenza pandemic. At the centre are the United Kingdom's four health departments, the NHS Executive and its regional offices, the Public Health Laboratory Service in England and Wales, the Scottish Centre for Infection and Environmental Health, the Medical Research Council, the National Institute of Biological Standards and Control, and the WHO Collaborating Centre for Influenza. At the periphery are health authorities or boards with public health departments trimmed to save management costs, autonomous NHS trusts, general practice in all its variety, independent nursing homes, and independent and local authority providers of residential and home care. It is right that preparations have been started to enable this unwieldy system to respond to a pandemic.

R T Mayon White Consultant in communicable disease control

Oxfordshire Health Authority, Oxford OX3 7LG

\footnotetext{
1 UK health departments' multiphase contingency plan for pandemic influenza. London: Department of Health, 1997.

2 Webster RG. While awaiting the next pandemic of influenza A. BMJ 1994;309:1178-9.

3 University of York NHS Centre for Reviews and Dissemination. Influenza vaccination and older people. Effectiveness Matters 1996;2(1).
} 